\title{
Características Físico-Mecânicas do Couro de Caprinos Mestiços Boer e Anglo Nubianos
}

\author{
Arturo Bernardo Selaive Villarroel ${ }^{1}$, Roberto Germano Costa $^{2}$, Sônia Maria Pinheiro Oliveira ${ }^{3}$
}

\begin{abstract}
RESUMO - As características físico-mecânicas de 22 couros de caprinos mestiços Boer e Anglo Nubianos foram avaliadas para determinação da qualidade quanto à resistência à tração e ao rasgamento. Os animais foram abatidos com idade média de 260 dias e peso corporal de 22,0 kg. Após a esfola, as peles foram pesadas, conservadas por salmouragem e salga e curtidas com sulfato de cromo. Para determinação da resistência à tração e ao rasgamento progressivo, foram retirados das regiões paleta, anca e ventre dos couros semi-acabados seis corpos-de-prova nas posições paralela e perpendicular à linha dorsal. O delineamento experimental utilizado foi o de parcelas subdivididas, tendo como parcelas dois grupos genéticos e como subparcelas o fatorial 2 x 3 (duas posições e três regiões), com três repetições, sendo as médias comparadas pelo teste Tukey. Não houve diferenças significativas de resistência entre os couros de ambos os grupos genéticos para os ensaios de tração e de rasgamento progressivo. Entretanto, observaram-se diferenças significativas entre as regiões paleta, anca e ventre em todos os parâmetros estudados nos ensaios de tração e de rasgamento progressivo, com os maiores valores de espessura, resistência e alongamento encontrados na paleta. Concluiu-se que o uso de reprodutores exóticos da raça Boer ou Anglo Nubiano em cruzamentos, para melhorar a produção de carne dos caprinos da região nordeste, não influencia a qualidade do couro dos animais.
\end{abstract}

Palavras-chave: caprinos, couro, ensaios físico-mecânicos, pele

\section{Physical-Mechanic Characteristics of Leather from Crossbred Boer and Anglo Nubiano Goats}

\begin{abstract}
The physical-mechanic industry characteristics of 22 crossed goat leathers from native does mated with Anglo Nubian (AG) and Boer (BO) bucks were studied to evaluate the leather quality by analysis of tension and tear resistance. Animals were slaughtered at average of 260 days of age and $22.0 \mathrm{~kg}$ of live body weigth. After skinning, the pelts were weighed, conserved in brine and salted and classified by quality before the chromium-tanned. To evaluate the tension and tear resistance assays, from the semi-finished leathers, six samples were taken in two directions from palette, hind and ventral regions. A split plot experimental design was used, where the two genetic groups were represented by the plots and a 2 x 3 factorial (two positions and three regions) by the split plots. Means were compared by Tukey test. No difference among groups in tension and tear resistance of leather assays were observed. However, there was a significant difference among samples from the palette, hind and ventral region in all characteristics studied, being thickness, strength and elongation valious higher in palette region. It was concluded that goat leather characteristics are similar for both genetic group and the quality is superior than the industry quality reference for a good product and the use of Boer exotic breed on crossing with native does to improve the meat production do not affect the leather quality of the animals.
\end{abstract}

Key Words: goats, skin, leather, mechanical characteristics

\section{Introdução}

A carne e a pele são os produtos de maior expressão na criação de caprinos no nordeste do Brasil. A pele representa, economicamente, 10 a $20 \%$ do valor do animal vivo, tendo atingido até $30 \%$, na década do 70 (Bellaver et al., 1979). As peles são de grande aceitação nos mercados nacional e internacional por apresentarem pêlos mais curtos e finos que os animais de clima temperado, proporcionando peles elásticas, macias e de alto valor comercial (Fernandes \& Rodrigues, 1991).

A qualidade da pele e do couro após o curtimento está relacionada ao manejo do animal durante sua criação, aos processos de abate, esfola, conservação, armazenamento e curtimento. Na indústria, a qualidade do couro é avaliada por ensaios físico-mecânicos, por meio da carga e resistência à tração, da

\footnotetext{
1 Professor do Departamento de Zootecnia da UFC. Bolsista do CNPq. Endereço eletrônico: selaive@ufc.br

2 Professor do Centro de Formação de Tecnólogos, Campus IV da UFPB. Endereço eletrônico: rgermano@cft.ufpb.br

3 Professor do Departamento de Zootecnia da UFC. Endereço eletrônico: soniace@ufc.br
} 
carga e resistência ao rasgamento e da resistência da flor à distensão, para atender determinados requisitos na comercialização de acordo com sua utilização (Jacinto, 1996).

Com a introdução de animais de raças exóticas no nordeste, visando melhorar o potencial de produção das raças nativas, podem ser alteradas as características desejáveis das peles para a indústria, o que pode reduzir seu valor comercial. Esta pesquisa foi conduzida com o objetivo de avaliar o efeito do cruzamento de reprodutores exóticos com as cabras nativas da região (SRD) sobre a qualidade dos couros por meio de ensaios físico-mecânicas de resistência à tração e ao rasgamento progressivo.

\section{Material e Métodos}

O trabalho foi desenvolvido no Setor de Ovinocaprinocultura do Departamento de Zootecnia da Universidade Federal do Ceará e nos Laboratórios das Indústrias privadas de Couro e Peles da região Bermas e C v Couros e Peles. Foram utilizadas vinte e duas peles de caprinos mestiços, machos inteiros, sendo nove peles de mestiços Anglo Nubiano x SRD e treze de Boer x SRD. Os animais foram abatidos com idade média de 260 dias e peso médio de 22,0 kg, em abatedouro industrial, conforme os métodos recomendados pelo Ministério de Agricultura e Abastecimento (BRASIL, 1980).

As peles foram curtidas de acordo com a metodologia descrita por Silva Sobrinho \& Jacino (1992), empregando-se as etapas do remolho, caleiro, desencalagem, purga, desengraxe, píquel, curtimento, basificação, neutralização, recurtimento e engraxe. Para o curtimento, utilizou-se como produto químico o sulfato de cromo.

No laboratório, por meio de ensaios físico-mecânicos, foram avaliadas as medidas de espessura, de resistência à tração e de alongamento e resistência ao rasgamento progressivo dos couros semi-acabados, segundo as normas da Associação Brasileira de Normas Técnicas-ABNT para o setor coureiro (ABNT, 1988; 1990; 1997abc; 1998). Antes da realização dos ensaios, os couros foram climatizados durante 48 horas sob temperatura de $23 \pm 2^{\circ} \mathrm{C}$ e umidade relativa de $50 \pm 5 \%$.

Dos couros semi-acabados foram retirados, do lado direito, seis corpos-de-prova das regiões paleta, anca e ventre, sendo três na direção paralela e três na direção perpendicular ao eixo crânio-caudal, utilizando-se o balancim (prensa hidráulica modelo BHV 22) com navalhas de dimensões e formato padronizado pelas respectivas normas. De cada amostra, composta de três corpos-de-prova, foram efetuadas as medidas de espessura, com auxílio de espessímetro, e posteriormente avaliados a resistência à tração e ao alongamento e rasgamento progressivo no dinamômetro (marca ZWICK/Z 2.5) acoplado a um computador com o programa “Test x pert standard test programs".

Para as análises dos dados, adotou-se o delineamento experimental inteiramente casualizado em um sistema de parcelas subdivididas, em que as parcelas foram representadas pelos dois grupos genéticos, com treze animais em um grupo e nove no outro, e as subparcelas, pelo fatorial 2 × 3 (duas posições e três regiões), com três repetições. As médias dos resultados dos ensaios físico-mecânicos foram comparadas pelo teste de Tukey, a 5\% de probabilidade, utilizando-se o procedimento de análise de variância do SAS (1999).

\section{Resultados e Discussão}

Os resultados dos ensaios físico-mecânicos referentes à tração e ao rasgamento progressivo dos couros foram similares $(\mathrm{P}>0,05)$ nas peles dos caprinos de ambos os grupos genéticos. Os valores de resistência à tração foram de 203,4 e 196,3kgf/ $\mathrm{cm}^{2}$, respectivamente, para os couros dos mestiços Anglo Nubianos e Boer (Tabela 1). As espessuras dos couros dos dois grupos genéticos, utilizadas no cálculo da resistência à tração, também não apresentaram diferença $(\mathrm{P}>0,05)$.

Os valores observados para espessura e resistência dos couros de ambos os grupos de caprinos encontram-se entre as médias relatadas na literatura para animais com a mesma idade, confirmando que os couros dos caprinos criados nessas condições apresentam qualidade industrial (BASF, 1984). Para resistência à tração, Costa et al. (1998) observaram valores de 197,14 kgf/ $\mathrm{cm}^{2}$ em couros de caprinos mestiços Anglo Nubianos abatidos aos 150 dias e de 218,44 kgf/ $/ \mathrm{cm}^{2}$ aos 300 dias de idade, demonstrando que, assim como a espessura, a resistência à tração também é maior à medida que avança a idade.

Médias de espessura de 0,95 e 1,02 mm foram relatadas por Costa et al. (1998) para o ensaio físico de carga de tração em couros de caprinos abatidos aos 150 e 300 dias de idade, respectivamente, confirmando também valores de espessura de 1,16 a 1,23 mm relatados por Jacinto (1993), em couros de ani-

R. Bras. Zootec., v.33, n.6, p.2369-2372, 2004 (Supl. 3) 
Tabela 1 - Valores médios dos ensaios físicomecânicos de tração e rasgamento em couros de caprinos mestiços em função do grupo genético

Table 1 - Average means for physical mechanical characteristics of tensilet and tearing in goat leather acordering with the genetic group

\begin{tabular}{|c|c|c|}
\hline $\begin{array}{l}\text { Fontes de variação } \\
\text { Sources of variation }\end{array}$ & $\begin{array}{c}\text { Mestiço } \\
\text { Anglo Nubiano } \\
\text { Half-breed } \\
\text { Anglo Nubiano }\end{array}$ & $\begin{array}{l}\text { Mestiço } \\
\text { Boer } \\
\text { Half-breed } \\
\text { Boer }\end{array}$ \\
\hline \multicolumn{2}{|l|}{ Tração } & Tensile \\
\hline $\begin{array}{l}\text { Espessura }(\mathrm{mm}) \\
\text { Thickness }(\mathrm{mm})\end{array}$ & $0,91^{\mathrm{a}}$ & $0,95^{\mathrm{a}}$ \\
\hline $\begin{array}{l}\text { Resistência }\left(\mathrm{kgf} / \mathrm{cm}^{2}\right) \\
\text { Strength }\left(\mathrm{kgf} / \mathrm{cm}^{2}\right)\end{array}$ & $203,43^{a}$ & $196,30^{\mathrm{a}}$ \\
\hline $\begin{array}{l}\text { Alongamento (\%) } \\
\text { Elongation (\%) }\end{array}$ & $43,05^{\mathrm{a}}$ & $43,95^{\mathrm{a}}$ \\
\hline \multicolumn{3}{|l|}{ Rasgamento progressivo } \\
\hline $\begin{array}{l}\text { Progressive tearing } \\
\text { Espessura (mm) } \\
\text { Thickness (mm) }\end{array}$ & $0,93^{\mathrm{a}}$ & $0,95^{\mathrm{a}}$ \\
\hline $\begin{array}{l}\text { Resistência }(\mathrm{kgf} / \mathrm{cm}) \\
\text { Strength }(\mathrm{kgf} / \mathrm{cm})\end{array}$ & $57,38^{\mathrm{a}}$ & $57,75^{\mathrm{a}}$ \\
\hline
\end{tabular}

mais de três anos, evidenciando que os couros de animais de maior idade apresentam maior espessura.

Também não houve diferença significativa $(\mathrm{P}>0,05)$ para a característica resistência ao rasgamento progressivo, demonstrando que tanto os couros de mestiços Anglo Nubianos quanto os de Boer apresentam boa resistência, uma vez que as médias de 57,38 e 57,75 observadas neste trabalho encontram-se acima do valor referencial de $50 \mathrm{kgf} / \mathrm{cm}$ estabelecido pela BASF (1984) (Tabela 1).

Em ambos os grupos genéticos, observou-se uma grande variação individual nos ensaios de tração e rasgamento progressivo entre as amostras das regiões da paleta, anca e ventre, bem como entre elas (Tabela 2), uma característica comum aos couros, que são produtos desuniformes por natureza.

A estrutura e a espessura da pele dos animais domésticos variam segundo a região e são influenciadas pela raça, idade e pelo sexo do animal (Bal, 1984). A região da paleta diferiu estatisticamente $(\mathrm{P}<0,05)$ em todos os parâmetros estudados nos ensaios físicomecânicos, apresentando os maiores valores de espessura, resistência à tração e alongamento. As diferenças

Tabela 2 - Valores médios dos ensaios físico-mecânicos de tração e rasgamento em couros de caprinos mestiços, segundo a região e posição das amostras

Table 2 - Average means for physical mechanical characteristics of tensilet and tearing in goat leather, according to the genetic group

\begin{tabular}{|c|c|c|c|c|c|}
\hline \multirow[b]{2}{*}{$\begin{array}{l}\text { Fontes de variação } \\
\text { Sources of variation }\end{array}$} & \multicolumn{3}{|c|}{$\begin{array}{l}\text { Tração } \\
\text { Tensile }\end{array}$} & \multicolumn{2}{|c|}{$\begin{array}{l}\text { Rasgamento progressivo } \\
\text { Tearing progressive }\end{array}$} \\
\hline & $\begin{array}{c}\text { Espessura } \\
(\mathrm{mm}) \\
\text { Thickness }(\mathrm{mm})\end{array}$ & $\begin{array}{c}\text { Resistência } \\
\left(\mathrm{kgf} / \mathrm{cm}^{2}\right) \\
\text { Strength }\left(\mathrm{kgf} / \mathrm{cm}^{2}\right)\end{array}$ & $\begin{array}{c}\text { Alongamento } \\
\text { (\%) } \\
\text { Elongation (\%) }\end{array}$ & $\begin{array}{c}\begin{array}{c}\text { Espessura } \\
(\mathrm{mm})\end{array} \\
\text { Thickness (mm) }\end{array}$ & $\begin{array}{c}\text { Resistência } \\
(\mathrm{kgf} / \mathrm{cm}) \\
\text { Strength }(\mathrm{kgf} / \mathrm{cm})\end{array}$ \\
\hline \multicolumn{6}{|l|}{ Região } \\
\hline Region & & & & & \\
\hline $\begin{array}{l}\text { Paleta } \\
\text { Shoulder }\end{array}$ & $1,01^{a}$ & $227,09^{a}$ & $44,65^{a}$ & $1,00^{a}$ & $67,74^{\mathrm{a}}$ \\
\hline $\begin{array}{l}\text { Anca } \\
\text { Rump }\end{array}$ & $0,93^{b}$ & $196,30^{b}$ & $39,59^{b}$ & $0,95^{b}$ & $54,60^{\mathrm{b}}$ \\
\hline $\begin{array}{l}\text { Ventre } \\
\text { Belly }\end{array}$ & $0,87^{\mathrm{b}}$ & $174,27^{\mathrm{b}}$ & $46,50^{\mathrm{a}}$ & $0,89^{\mathrm{c}}$ & $50,45^{\mathrm{C}}$ \\
\hline Posição & & & & & \\
\hline $\begin{array}{l}\text { Position } \\
\text { Perpendicular } \\
\text { Pernendicular }\end{array}$ & $0,93^{\mathrm{a}}$ & $213,32^{\mathrm{a}}$ & $36,21^{b}$ & $0,93^{\mathrm{a}}$ & $57,02^{\mathrm{a}}$ \\
\hline $\begin{array}{l}\text { Paralela } \\
\text { Parallel }\end{array}$ & $0,94^{\mathrm{a}}$ & $185,18^{b}$ & $50,95^{\mathrm{a}}$ & $0,96^{\mathrm{a}}$ & $58,17^{\mathrm{a}}$ \\
\hline
\end{tabular}

Valores seguidos por letras distintas, na mesma coluna, indicam diferença significativa a $5 \%(P<0,05)$, pelo teste Tukey. Values followed by different letters, in the same column, indicate significant difference level at $5 \%(P<.05)$ by Tukey test. 
entre as regiões podem ser atribuídas às características estruturais de cada couro, graças ao arranjo das fibras de colágeno (Ferrandizgomez et al., 1993). Estes resultados são coerentes considerando que a paleta está próxima à zona do grupão, que é a região mais rica em fibras de colágeno, responsáveis pela textura e resistência do couro (Freire \& Canl, 2000). A região do flanco, por sua vez, é uma zona pobre em fibras de colágeno, com entrelaçamento mais fraco em relação às demais regiões.

Os resultados referentes à posição das amostras apresentaram também diferenças significativas $(\mathrm{P}<0,05)$ nos parâmetros resistência e alongamento somente para o ensaio de tração (Tabela 2). Os valores para posição, no parâmetro resistência à tração, estão dentro das especificações do SENAI (Hoinacki, 1989), que estabelece um mínimo de $180 \mathrm{kgf} / \mathrm{cm}^{2}$, porém inferior aos $250 \mathrm{kgf} / \mathrm{cm}^{2}$ especificados pela BASF (1984).

Os valores de resistência à tração nas amostras de posição perpendicular foram superiores $(\mathrm{P}<0,05)$ aos de posição paralela (213,3 e 185,2 kgf/cm², respectivamente), diferentemente do alongamento, que apresentou valores superiores nas amostras de posição paralela (50,9\% e 36,2\%), em virtude do arranjo das fibras de colágeno, como também foi abservado por Jacinto (1996) na região da paleta.

\section{Conclusões}

As peles de caprinos mestiços oriundas de cabras SRD com reprodutores das raças Boer e Anglo Nubiano no nordeste não apresentam diferenças significativas na qualidade do couro. Portanto, o uso em cruzamento de reprodutores exóticos da raça Boer, para melhorar a produção de carne dos caprinos da região, não influencia a qualidade dos couros nos animais mestiços.

\section{Agradecimento}

Às empresas Bermas Indústria e Comércio Ltda e CV. Couros e Peles Ltda, pelas facilidades para execução do projeto, pela estrutura laboratorial e pela disponibilização de pessoal.

\section{Literatura Citada}

ASSOCIAÇÃO BRASILEIRA DE NORMAS TÉCNICAS. NBR 11035, NB 1199: corte de corpos-de-prova em couro. Rio de Janeiro, 1990. 1p.

R. Bras. Zootec., v.33, n.6, p.2369-2372, 2004 (Supl. 3)
.NBR 11052, MB 2984: couros - determinação da espessura.

Rio de Janeiro, 1997a. 3p.

.NBR 11055, MB 3015: couro - determinação da força de rasgamento progressivo. Rio de Janeiro, 1997c. 4p.

.NBR 11041, MB3013: couros-determinação da resistência à tração e alongamento. Rio de Janeiro, 1997b. 5p.

.NBR 10455, NB 1123: climatização de materiais usados na fabricação de calçados e correlatos. Rio de Janeiro, 1988. 3p. .NBR 11032, NB 1196: peles e couros - tomada de pedaçode-prova - procedimento. Rio de Janeiro, 1998. 4p.

BAL, H.S. Pele. In: Dukes fisiologia dos animais domésticos. 10.ed. Rio de Janeiro: Guanabara Koogan, 1984. p.469-477.

BASF. Vademécum para el técnico en curtición. 2.ed. Ludwigshafen: 1984. 441p.

BELLAVER, C.; OLIVEIRA.E. R.; FIGUEIREDO, E.A.P. O peso como fator técnico-econômico da comercialização de peles de caprinos e ovinos tropicais. Sobral: EMBRAPA-CNPC, 1979. 3p

BRASIL - Ministério de Agricultura e Abastecimento. Regulamento da Inspeção Industrial e Sanitária de Produtos de Origem Animal. RISPOA. Brasília, 1980. 166p.

CENTRO TECNOLÓGICO DO COURO CALÇADOS E AFINS. A fabricação do couro. Novo Hamburgo, 1994. 44 p. (Série Couro Calçados e Afins, 1).

COSTA, R.G.; PIMENTA FILHO, E.C.; SILVA, A.F.R. et al. Efeito da idade do animal na qualidade do couro de caprinos criados em regime semi - extensivo. Revista Brasileira de Zootecnia, v.27, n.2, p.355-358, 1998.

FERNANDES, A W.; RODRIGUES, M.R.C. Avaliação das peles de pequenos animais a nível de industria de curtume. Ciência Animal, v.1, p.113, 1991.

FERRANDIZGOMEZ, T.P.; ALMELA, M.; MARTINMARTINEZ, J.M. et al. Effect of skin type and direction of applied force on peel strength of skin layers. Journal of the Society of Leather Technologists and Chemists, v.77, n.4, p.115-122, 1993.

FREIRE, M.C.; CANL, R.M. A pele bovina como matéria-prima. Revista Nacional da Carne, v.24, n.283, p.100-110, 2000.

HOINACKI, E. Peles e couros: origens, defeitos e industrialização. 2. ed. Porto Alegre: CPF SENAI de Artes Gráficas "Henrique d“Ávila Bertaso”, 1989. 320p.

JACINTO, M.A.C. O couro caprino produzido no Brasil. Jaboticabal: Universidade Estadual de São Paulo, 1993. 45p. Monografia (Especialização) - Universidade Estadual de São Paulo, 1993.

JACINTO, M.A.C. Características anátomo-estruturais da pele de ovinos (Ovis áries L.) lanados e deslanados, relacionadas com o aspecto físico-mecânico do couro após o curtimento. Jaboticabal: Universidade Estadual de São Paulo, 1996. 90p. Dissertação (Mestrado em Zootecnia) - Universidade Estadual de São Paulo, 1996.

STATISTICAL ANALYSES SYSTEM - SAS. The SAS system for windows. version 8.0. Cary: 1999.

SILVA SOBRINHO, A.G.; JACINTO, M.A.C. Peles ovinas. 1.ed. Jaboticabal: FUNEP, 1992. 33p.

Recebido em: 04/02/03 Aceito em: 26/07/04 